\title{
A GENERALIZATION OF THE HILBERT'S TYPE INEQUALITY
}

\section{GAOWEN XI}

Abstract. In this paper, by introducing two parameters $A, B$ and using the Euler-Maclaurin expansion for the Riemann zeta function, we establish an inequality of a weight coefficient. Using this inequality, we derive generalizations of a Hilbert's type inequality.

Mathematics subject classification (2010): 26D15.

Keywords and phrases: Hilbert's type inequality, weight coefficient, Hölder's inequality, generalization, reinforcement.

\section{REFERENCES}

[1] G. H. Hardy, J. E. Littlewood and G. Polya, Inequalities, Cambridge Univ. Press, 1934.

[2] Jichang Kuang And L. Debnath, On new generalizations of Hilbert's inequality and their applications, J. Math. Anal. Appl., 245, (2000), 248-265.

[3] K. Knopp, Theory and application of infinite series, Blackie \& Son Limited, London, 1928.

[4] M. KRniĆ And J. PeČArić, General Hilbert's and Hardy's inequalities, Math. Inequal. Appl., 8, 1 (2005), 29-51.

[5] GaOWen XI, On generalizations and reinforcements of a Hilbert's type inequality, Rocky Mountain Journal of Mathematics, 42, 1 (2012), 329-337.

[6] B. YANG, A new Hilbert-type inequality, Bull. Belg. Math. Soc., 13, (2006), 479-487.

[7] B. YANG, On best extensions of Hardy-Hilbert's inequality with two parameters, J. Inequal. Pure Appl. Math., 6, 3 (2005), Article 81.

[8] B. YANG, On a Strengthened version of the more accurate Hardy-Hilbert's inequality, Acta. Math. Sinica, 42, 6 (1999), 1103-1110.

[9] B. YANG AND Y. ZHU, Inequality on the Hurwitz Zeta-function restricted to the axis of positive reals, Acta Scientiarum Naturalium Universitatis Sunyatseni, 36, 2 (1997), 30-35. 